\title{
Movilidad y estabilidad de las poblaciones en el mundo romano: una reflexión metodológica e historiográfica
}

\author{
Greg WoolF \\ Institute of Classical Studies. London \\ Greg.Woolf@sas.ac.uk
}

Recibido: 14 de octubre de 2015

Aceptado: 2 de mayo de 2016

\section{RESUMEN}

El presente artículo tiene como objetivo hacer una reflexión sobre las posibilidades de estudio de la movilidad en el mundo antiguo y en concreto en el Imperio romano. Para ello parte de un análisis de la obra The Corrupting Sea de N. Purcell y P. Horden y de estudios sobre la movilidad según la han estudiado los arqueólogos para época prehistórica y los demógrafos modernos para tiempos más recientes. Como conclusión se argumenta que, a pesar de las limitaciones de la documentación antigua para conocer en detalle el fenómeno, es posible sostener la existencia de una movilidad limitada cuantitativamente, pero que suponía un importante grado de conectividad en el mundo romano.

Palabras clave: Roma. Viajeros. Residentes. Demografía. Conectividad.

\section{Mobility and Stability of the Population in the Roman World: A Methodological and Historiographical Discussion}

\begin{abstract}
This paper examines the potential for human mobility in the ancient world and in particular in the Roman Empire. It begins from a consideration of Horden and Purcell's The Corrupting Sea and also draws on studies of mobility conducted by prehistorians and by historical demographers working on more recent periods. Detailed information on the phenomenon is lacking. Nevertheless is it possible to argue from this that the extent of mobility was relatively limited, yet still sufficient to maintain important levels of connectivity across the Roman World.
\end{abstract}

Keywords: Rome. Movers. Stayers. Demography. Connectivity.

Sumario: 1. ¿Un mundo móvil? 2. Los argumentos a favor de la movilidad. 3. Los límites de la movilidad. 4. Migración y movilidad. 5. ¿Era la movilidad en su mayor parte de corto recorrido? 6. Flujos migratorios. 7. Una revisión de la movilidad a larga distancia. 8. Viajeros y residentes. 


\section{1. ¿Un mundo móvil? ${ }^{1}$}

En la actualidad la importancia de la movilidad en las sociedades antiguas no necesita demostración. La investigación de las últimas décadas ha dejado obsoleta la imagen que los demógrafos trataron de presentar de poblaciones casi por completo inmóviles. En la cuenca del Mediterráneo, durante mucho tiempo, desde la Antigüedad hasta períodos recientes, la circulación de personas ha constituido un hecho que es a la vez estructural y estructurante, un elemento de continuidad que forma la verdadera esencia de una red mediterránea. ${ }^{2}$

Claudia Moatti, cuya investigación ha hecho tanto para ilustrar la movilidad humana a lo largo del Mediterráneo en tiempos antiguos y modernos, ${ }^{3}$ ha sintetizado de forma breve el consenso actual. ${ }^{4}$ Como historiadores y arqueólogos del mundo clásico insistimos ahora repetidamente en los conceptos de movimiento, comunicación, movilidad y conectividad, hibridación y cosmopolitismo. Nuestra fascinación por el movimiento y el intercambio es evidente en los análisis revisionistas de la economía romana, en los estudios sobre la novela antigua entre Oriente y Occidente, en los proyectos que rastrean diásporas a través de la distribución de haplotipos y del análisis de isótopos estables, y en las múltiples aplicaciones de la crítica poscolonial y de la teoría de la globalización. En parte se trata, simplemente, de la última versión de la tradicional tendencia a reclamar la modernidad de los antiguos.

Podemos admitir que el mundo clásico no estuvo nunca poblado de comunidades remotas, aisladas y autárquicas. De hecho, es difícil pensar que alguien pudiera estar en desacuerdo con la afirmación de Moatti, según la cual en realidad es debatible que las anteriores generaciones de geógrafos intentaran persuadirnos de que estas poblaciones eran en general inmóviles. No obstante, afirmar la movilidad de las sociedades antiguas como un elemento de continuidad plantea nuevas cuestiones, pues ahora se apela a la movilidad como un fenómeno importante para cualquier período de la Historia. Se argumenta razonablemente que la capacidad de movilidad es una de las características que distingue a nuestra especie de otras cercanas, vivas o extintas, que el ser humano es móvil de forma innata y que indicios de nuestra adaptación a la movilidad pueden encontrarse en los procesos cognitivos o digestivos, en nuestra sociabilidad y en el uso del lenguaje. ${ }^{5}$ De ello se sigue que no basta con afirmar que las antiguas poblaciones eran móviles: hace falta considerar de qué forma se movía la gente y de qué modo diferentes tipos de movilidad variaron a lo largo de este período

1 Agradezco a los asistentes al workshop Mobility and migration in the Roman world, celebrado en el Koninklijk Nederlands Instituut de Roma en junio de 2015, y al público del Instituto Joukowsky de la Universidad de Brown sus comentarios, que han contribuido a mejorar significativamente los argumentos de este artículo. La responsabilidad por las opiniones expresadas y por los posibles errores es por completo mía. Agradezco igualmente la traducción de este trabajo, originalmente escrito en inglés, a la Dra. Ana Rodríguez Mayorgas.

2 MoATti 2013, 77.

3 Mohtti 2004; EAD. 2006; MoATti - KaISER 2007.

4 Comparar, por ejemplo, con Purcell 1990, 2005; Osborne 2009, 123.

5 Ver recientemente EARle - Gamble - Poinar 2011; Wells - Stock 2012. Para una visión de conjunto NESS 2013. 
histórico y entre la Antigüedad y otros momentos anteriores y posteriores. Esto inevitablemente supone algún intento de cuantificación, aunque sea aproximada. Tenemos que preguntarnos: ¿quién se movía?, ¿con qué frecuencia?, y ¿a qué distancia? Por último, también requiere preguntarnos por la estabilidad, preguntarnos tanto por los que permanecían como por los que se movían. ¿Quiénes eran los menos móviles en relación a los demás? ¿En qué medida se distinguían por su edad, sexo, ocupación, habilidades, riqueza u otros factores con respecto a los más móviles? Y, ¿cómo se relacionaban unos y otros?

\section{Los argumentos a favor de la movilidad}

En este punto quizá sería útil recordar brevemente por qué todos creemos hoy en día en la movilidad. La primera razón es que muchos textos antiguos hablan de movimientos de pueblos y de individuos. ${ }^{6}$ Dichos movimientos van desde los relatos sobre los nostoi y ktiseis (leyendas de fundación) hasta las historias de primaveras sagradas (ver sacrum), pasando por los relativos a las invasiones bárbaras, las narraciones históricas de colonizaciones y deportaciones, y los programas de asentamiento y de inmigración hacia grandes ciudades. Para el período romano tenemos también algunos relatos de viajes privados realizados por negocios o en misión oficial, incluso por turismo y peregrinaje. ${ }^{7}$ Por supuesto, existen los problemas usuales de interpretación de la documentación: ¿cómo deberíamos interpretar los relatos de migraciones arcaicas?, ¿cómo reconstruimos los patrones de movimientos regulares cuando las fuentes históricas a menudo dan por supuesto lo común y prestan atención a los acontecimientos extraordinarios?, ¿podemos confiar en los números que dan, cuando por suerte llegan a dar alguno? Pero todos estos no son problemas insuperables, de hecho, aprender a lidiar con ellos es parte de la formación de los historiadores de la Antigüedad.

Una segunda razón para creer en la movilidad es el testimonio que aportan las que podríamos denominar "diásporas materiales", ${ }^{8}$ esto es, la dispersión de objetos que dejan tras de sí los humanos. Estas dispersiones se conocen mucho mejor ahora gracias a los avances arqueológicos en la detección de procedencias, ya sea por métodos tradicionales o a través de la excavación de hornos, el análisis petrológico de la cerámica, el análisis de isótopos del metal y otros tantos métodos. La procedencia de materiales orgánicos tales como semillas, fruta disecada, o muestras de madera, es también cada vez más fácil de rastrear; por su parte, el análisis de isótopos estables aplicado a esqueletos humanos está consiguiendo idénticos logros con respecto a la identificación de la procedencia de los individuos. Para la Edad de Bronce ya se ha avanzado mucho en este sentido, aunque la cantidad total de materiales recuperados es muy pequeña comparada con la de períodos posteriores. ${ }^{9}$ Una vez en marcha la

6 BiCKermann 1952; WoOlF 2011.

7 Adams - Laurence 2001; Adams - Roy 2007; Elsner - Rutherford 2005; CASSON 1974.

8 Se emplea el término diáspora en un sentido metafórico, de ahí el entrecomillado.

9 Manning - Hulin 2005; Dommelen - Knapp 2010. Para la cuestión de la escala ver Blake 2008. 
expansión de la primera Edad de Hierro, el número de las "diásporas materiales" y su potencial dimensión se multiplican. Así, skyphoi decorados con motivos semicirculares de Eubea, sellos del tañedor de lira de Siria, escarabeos de fayenza de Egipto, y una variada gama de tipologías de vajillas y ánforas, han sido utilizados para elaborar mapas de distribución. No siempre es fácil rastrear la circulación de estos objetos desde sus lugares de producción hasta su destino final, pero podemos inferir bastante información. También se perciben algunas limitaciones en la circulación: un ejemplo es la casi total ausencia de materiales egeos en Egipto o en la región del Mar Negro antes del 700 a.C., lo que nos indica el límite geográfico y cronológico de cierto tipo de movilidad. Con anterioridad se detecta la aparente ruptura de intercambios entre el Mediterráneo oriental y el occidental al final de la Edad de Bronce. Desde mediados del primer milenio a.C. tenemos monedas e inscripciones, que en muchos aspectos pertenecen a la simple categoría de artefactos arqueológicos, pero que ofrecen más información sobre quienes las hicieron y utilizaron gracias a los textos que llevan inscritos. En la base de todas estas "diásporas materiales" está el movimiento de individuos.

Una tercera razón para creer en la movilidad proviene de la ecología. A medida que hemos ido tomando conciencia de las dificultades que tiene la agricultura en el ámbito del Mediterráneo, la idea de que comunidades de cualquier dimensión pudieran haber sido genuinamente autárquicas, es decir, totalmente autosuficientes en recursos, parece más difícil de creer. ${ }^{10}$ Resulta evidente desde hace tiempo que la mayoría de las poblaciones neolíticas tenían que moverse para encontrar obsidiana. ${ }^{11}$ La precariedad ecológica de muchos de los entornos que explotaban los primeros agricultores sugiere que para superar años malos confiaban en una red de conexiones y obligaciones con sus vecinos. ${ }^{12} \mathrm{Y}$ los malos años eran usuales, al menos a escala local. La fragmentación ecológica y climática de los paisajes mediterráneos sugiere que en un mismo año una micro-región podía experimentar prosperidad mientras que sus vecinas se enfrentaban a la escasez; precisamente, esta divergencia se ha señalado como un incentivo para el comercio y para la formación del Estado. El crecimiento del tamaño de los asentamientos durante el primer milenio a.C. simplemente agravó el problema. ${ }^{13}$ Las grandes ciudades comenzaron a depender del abastecimiento regular de comida procedente de lugares más ricos y seguros más allá del Mediterráneo, tales como el valle del Nilo y el sur de Rusia. La urbanización concentró la demanda en unos pocos lugares y generó conexiones con áreas que suministraban textiles y metales, combustible y piedra, agua y animales, además de muchos objetos de lujo. También el ser humano era un recurso que podía ser objeto de movimiento o que se movía por sí mismo con el fin de mantener ese mundo en funcionamiento.

\footnotetext{
10 Sallares 1991 y más recientemente Harris 2013.

11 Torrence 1986; Broodbank 2010.

12 Halstead - O’Shea 1982.

13 GARNSEY 1988.
} 
Al enumerar estas razones queda claro que nos enfrentamos a una gran variedad de tipos de movilidad. ${ }^{14}$ Los "héroes viajeros" 15 de tiempos homéricos que describe Lane Fox habitaban un mundo diferente del de los héroes neolíticos de Broodbank que, remando, llegaban en canoa hasta la deshabitada isla de Melos en busca de obsidiana. Y un nivel diferente representan los grandes convoys de barcos cargados de trigo que regularmente viajaban de Crimea a Atenas en los siglos V y IV a.C. o de Alejandría y Cartago a Roma a comienzos del Imperio. Pero, además, no se trata solo de una cuestión de escala diferente, aunque esta también es parte de la historia. Resulta extraño utilizar un único término, "movilidad", para referirse tanto a comerciantes que hacían viajes regulares como a las masas que se hacinaban en las metrópolis del Mediterráneo. Muchos de los que hacían un solo viaje a Roma o a Alejandría lo hacían encadenados. ${ }^{16}$ Colonos y comerciantes, podemos suponer, contaban con una riqueza y salud por encima de la media. La movilidad forzosa de soldados y esclavos tenía un carácter -y también unas consecuencias- diferentes, comparada con los movimientos estacionales de aquellos que buscaban trabajo en áreas dedicadas al cultivo de vino, o de los que se trasladaban en verano a las ciudades para trabajar ya fuera en los puertos durante el período de navegación o en los proyectos de construcción. Por otro lado, estaba el movimiento de ciudadanos libres que tenían la esperanza de enriquecerse pero que, a menudo, terminaban muriendo en las ciudades o en las minas. Los debates políticos actuales sobre inmigración muestran la completa falta de comprensión que deriva de la incapacidad de distinguir entre los distintos tipos de movilidad humana. La movilidad antigua pudo ser prácticamente igual de variada, $\mathrm{y}$, al igual que los episodios de migración masiva de los últimos quinientos años, que cuentan con un mejor registro, debió de variar de forma considerable de un período a otro.

Como punto de partida, planteo que todo estudio riguroso sobre la movilidad humana en la Antigüedad debería tener en cuenta al menos tres factores. En primer lugar, debería diferenciar entre distintos tipos de movilidad (larga y corta distancia, permanente o temporal, etc.) y también entre distintos tipos de inmigrantes (individuos y grupos, mujeres y hombres, voluntarios o forzados, etc.). Además, debería considerar el cambio a lo largo del tiempo, y centrarse en la variabilidad de la movilidad como una fuerza estructurante y no simplemente como un hecho estructural o una constante en la historia del Mediterráneo. En pocas palabras, es necesario hacer una historia de la movilidad. ${ }^{17}$ Por último, requiere llevar a cabo cierta cuantificación, por la misma razón por la que no es suficiente hablar de comercio o de producción en términos excesivamente vagos, tales como "activo", "importante", o "significativo". Aunque sea de forma aproximada necesitamos saber cuánta gente se movía, y con qué frecuencia, y cuánta gente permanecía estable. ${ }^{18}$

14 Un argumento clave de ERDKAmp 2008 del que es deudora gran parte de la discusión del presente artículo.

15 LANE FOX 2008.

16 SCHEIDEL 1997.

17 Sobre esta cuestión BRESSON 2005, 104.

18 FinLey 1973, 32-34. 
De acuerdo con estas ideas, es mi intención en este artículo presentar algunas propuestas preliminares.

\section{Los límites de la movilidad}

En la actualidad cualquier debate sobre movilidad en la Antigüedad tiene que partir de la impresionante y original obra de Horden y Purcell, The Corrupting Sea, una publicación que, una década y media después de su aparición, marca aún la línea a seguir en la investigación sobre los aspectos sociales y económicos del Mediterráneo antiguo. The Corrupting Sea mantiene una posición similar a la de Moatti y de forma repetida sostiene la idea de que la movilidad humana está sistemáticamente infrarrepresentada en las fuentes antiguas y es subestimada por los investigadores modernos.

La visión de Horden y Purcell sobre la movilidad no se presenta de forma ordenada, sino que aparece dispersa a lo largo de toda la obra, especialmente en los capítulos 5,7 y 9 , con frecuentes referencias cruzadas. Por ello no es fácil condensar sus argumentos en una o varias ideas. Aunque en su conjunto el libro está estructurado temáticamente, en gran medida se compone de descripciones resumidas sobre lugares concretos o casos específicos. Evidentemente, este esquema es deliberado, pues el orden temático permite explorar las continuidades sin la distracción que supone una narrativa histórica, mientras que los ejemplos particulares sirven para enfatizar la diversidad y las diferencias que los autores advierten como características de cada región. Esta estructura fractal es repetida en cada capítulo y en cada apartado, mientras que los argumentos son extraídos de un impresionante registro de testimonios, en su mayoría literarios, con cronologías y procedencias geográficas muy variadas.

El mundo que presentan se extiende al menos durante tres milenios e incluye amplios territorios del hinterland continental del mar Mediterráneo.$^{19} \mathrm{El}$ método elegido tiene como finalidad persuadir al lector mostrando ejemplos -todos ellos refrendados por un amplio conjunto de testimonios- que dan peso a las asunciones iniciales, pero éstas no se contrastan con contra-argumentos posibles o reales, ni se presentan como hipótesis que deban ser probadas por los datos. Por fortuna, los autores han clarificado posteriormente, y por separado, sus intenciones y a través de sus respectivos artículos se puede obtener una idea más clara de cómo conciben la movilidad. Así, por ejemplo, en el resumen que hizo del libro en 2004, Purcell afirmaba que los argumentos utilizados se basaban en una triple descripción de la obtención de productos primarios en relación a un determinado patrón de riesgo: una lógica de producción organizada para enfrentarse a este riesgo; un reconocimiento de la extremada fragmentación topográfica de la región y, por último, un régimen especial de comunicaciones. ${ }^{20}$

Partiendo de esta base, los autores habían argumentado que "la conectividad era el factor variable que permitía valorar las características sociales y económicas de una

19 Sobre los límites del estudio ver HARRIs 2005.

20 Purcell 2004, 10. Ver también Horden 2005, 179 y 182. 
región del Mediterráneo en un momento histórico dado". La afirmación no contradecía lo dicho por Horden, pero la formulación de Purcell reconocía de forma implícita la importancia del "momento histórico concreto". A pesar de las constantes apelaciones a la continuidad, a menudo reflejadas en la yuxtaposición de acontecimientos y textos de períodos distintos, la obra The Corrupting Sea ha sido injustamente acusada de descuidar la Historia. En ocasiones la decisión de no tratar la cuestión del cambio es justificada por la escasez de testimonios disponibles, y es este, precisamente, el argumento que los autores esgrimieron para dejar de lado las variaciones en los niveles de la movilidad. ${ }^{21}$

Pero, en general, es evidente que los autores de The Corrupting Sea decidieron deliberadamente dar preferencia al análisis y la presentación sincrónica sobre la diacrónica. Con su empeño en unir materias que con anterioridad estaban divididas por la periodización convencional, tomaron un camino menos transitado por otros historiadores de la Historia Antigua o Medieval, a quienes el interés por la narración política y el cambio llevó a descuidar el medio físico en el cual se desarrollan los acontecimientos históricos. El precio que comporta adoptar una postura de este tipo es evidente y muchas respuestas y réplicas a esta obra han llamado la atención sobre las consecuencias que entraña no dar un mayor peso a los grandes cambios tecnológicos, por ejemplo en la navegación y en la variedad de cultígenos disponible, o no considerar variables tales como la proporción de la población que no estaba vinculada a la agricultura o, incluso, el propio tamaño de la población. ${ }^{22}$ Es posible. Pero es fácil entender de qué forma llegaron a estos presupuestos leyendo los párrafos iniciales de la obra. ${ }^{23}$ En ellos se aprecia que la búsqueda de una unidad y particularidad del mundo mediterráneo, o de sus continuidades al estilo de la longue durée de Braudel (o pre-braudeliana), hace que la obra recurra constantemente al lenguaje de la conectividad y la movilidad, dos términos que, en consecuencia, se han convertido en clave del debate actual sobre la movilidad humana. La conectividad, concebida como la característica bien de una micro-región, bien de todo el Mediterráneo, va indisolublemente unida, en la obra de estos autores, a la movilidad como característica de pueblos e individuos. Aunque está basado en algunas de las consideraciones ecológicas y geográficas que ya destacaron Halstead y Garnsey, entre otros, el análisis de Horden y Purcell rechaza de forma insistente el determinismo medioambiental. Da la sensación de que prefieren considerar la conectividad como un elemento potencial y la movilidad como el medio para llevarlo a cabo. Imaginan el Mediterráneo como un conjunto de áreas interconectadas, sin mucha fricción, a través del cual la movilidad de todo tipo es relativamente fácil.

Estas áreas estaban rodeadas y delimitadas por territorios de más difícil comunicación, montañas y bosques, desiertos y tierras continentales, regiones de una conec-

21 Horden - Purcell 2000, 400.

22 Horden - Purcell 2000. Este no es el lugar de ofrecer otra revisión de la obra, que ya ha inspirado dos volúmenes como respuesta MALKIN (ed.), 2005; HARris (ed.), 2005, y un buen número de reseñas, especialmente SHAw 2001; FENTRESS - Fentress 2001.

23 Horden - Purcell 2000, 9. 
tividad relativamente baja. ${ }^{24}$ Este argumento es incontestable, de hecho su contrario, es decir, la idea de que el movimiento era fácil y frecuente de igual modo en todas direcciones e independientemente del territorio, sería ridículo. La cuestión no estriba en si estas condiciones y sus consecuencias eran reales (claramente lo eran), sino hasta qué punto eran relevantes. Podemos comparar este problema con el que planteaba la argumentación de Keith Hopkins a favor de una conexión entre impuestos, crecimiento económico, comercio y urbanización. ${ }^{25}$ Nadie se atrevería a sostener que la tributación no estimulaba la producción, ni que carecía de consecuencias económicas el hecho de que los emperadores invirtieran en un número menor de territorios en comparación con el de aquellos en los que recaudaban impuestos. La verdadera pregunta es qué parte de la actividad económica puede explicarse de este modo. De igual forma, en relación con la movilidad, no se trata de cuestionar si las micro-regiones del Mediterráneo estaban conectadas entre sí -por supuesto que lo estaban- sino en qué medida esto era significativo; en otras palabras, qué grado de movilidad permitían estas conexiones y, al contrario, qué tendencia a la inmovilidad tenían las poblaciones antiguas. Pues, del mismo modo que los mercados no están perfectamente integrados hasta el punto de fijar precios de una manera totalmente racional, tampoco es cierto que los paisajes reales estén tan perfectamente conectados como para que la movilidad sea siempre óptima. Algunos espacios del Mediterráneo posiblemente fueron áreas de difícil comunicación, pero ninguno estuvo libre de este fenómeno. Solo los estudios cuantitativos o los modelos paramétricos -ninguno de los cuales destaca especialmente en la obra The Corrupting Sea- pueden ayudar a contestar esta pregunta.

El énfasis en la conectividad y la movilidad va acompañado de la afirmación de que la densidad de población del área mediterránea fue en general baja. Los seres humanos podían ser tratados, de esta forma, como un recurso escaso, un recurso que a menudo tenía que ser trasladado con el fin de explotar todo su potencial. ${ }^{26}$ Los individuos, o bien se movían por voluntad propia para obtener su sustento, o bien formaban parte de un recurso movilizado por los estados imperialistas o por los traficantes de esclavos en beneficio de otros. Como resultado de ello, los seres humanos se acumulaban en el centro de redes -como en islas con altas densidades de población o en lugares de alta intensidad económica, tales como minas, ciudades o villas estatales-y se dispersaban rápidamente cuando las conexiones variaban o la producción económica local disminuía. La afirmación de que las poblaciones del Mediterráneo antiguo rara vez cayeron en una "trampa malthusiana" es muy verosímil y la respuesta de Horden y Purcell a las explicaciones de la movilidad basadas en la escasez de tierras o en el exceso de población es igualmente convincente. La "elasticidad" de la población, es decir, el grado de facilidad con que la gente se movía, es una cuestión que permanece debatida. ¿Con qué facilidad, de forma realista, podía una población antigua cambiar de localización como consecuencia de un desastre económico?

24 PurCell 2004.

25 Hopkins 1978a; ID. 1980; ID. 1995/6; ID. 2000.

26 Horden - Purcell 2000, 266-328, 377-391. 
En la actualidad estamos familiarizados con las consecuencias que, a largo plazo, provoca la destrucción de la industria en una localidad concreta: cuando una mina de carbón deja de funcionar, se agotan los bancos de pescado, o el precio del cobre se desploma a escala mundial, comunidades enteras pueden sumergirse en una pobreza que se prolonga durante generaciones. En algunos casos la dispersión se presenta como una opción: así lo indica, por ejemplo, la despoblación sufrida por Detroit tras el desplome de la industria norteamericana del motor. Pero no siempre es seguro encontrar un nuevo hogar y trabajo. De modo que si la ubicación de las poblaciones rara vez es óptima en la actualidad, ¿por qué habríamos de pensar que era más sencillo en la Antigüedad? Teniendo en cuenta que entonces los medios de transporte eran menos eficientes y que la proporción de la población que tenía ocupaciones que implicaban movilidad era menor que aquella dedicada al trabajo de la tierra, nos podemos preguntar cuánto suponía para una población antigua responder a los cambios en la conectividad y qué repercusiones tenían, en términos cronológicos, económicos y humanos, los lapsos de tiempo que se producían entre los cambios en los recursos y la respuesta humana a través de la movilidad.

La contribución a la actual discusión sobre la movilidad humana que aporta la obra The Corrupting Sea es desigual. Por un lado, presenta un conjunto de argumentos convincentes sobre cómo deben relacionarse la movilidad y la conectividad. La ecología y el paisaje del Mediterráneo no empujan a la movilidad y sí la constriñen de algún modo; $\mathrm{y}$, sin embargo, la movilidad se convirtió en una opción importante tanto para los individuos como para los Estados. Al tratar el trabajo humano (o a los seres humanos, los usos varían) como cualquier otro recurso limitado, se generó una lógica económica que supuso la localización y movilización de mano de obra en determinados momentos. Por otro lado, las conexiones que traza el libro son en esencia lógicas y no empíricas, y su significado -la magnitud de su influencia- no puede valorarse fácilmente. Quedan por establecer, entre otros, las tendencias de la conectividad, las cifras de individuos en movimiento, y las micro-regiones más o menos afectadas por estos factores. Se pueden plantear, además, otras cuestiones con respecto al hinterland continental del Mediterráneo, un espacio que aparece solo de forma tangencial en The Corrupting Sea. Este mar no ha sido en ningún momento un sistema cerrado y, de hecho, en períodos históricos ha habido episodios de migraciones masivas dentro y fuera de la Europa templada y esteparia. ${ }^{27}$ Este área debería ser considerada también en una explicación más detallada de las migraciones en la Antigüedad clásica. Por último, la preocupación de los autores por enfatizar todo tipo de movilidad les lleva a diferenciar de forma sistemática, solo en contadas ocasiones (como su importante discusión sobre el cabotaje), los diversos tipos de movimiento; y en su defensa apasionada de las estructuras duraderas de la vida en un Mediterráneo "previo a Braudel" han dejado para otros la tarea de analizar el cambio a lo largo del dilatado período que abarcan, y también la de establecer los límites de la movilidad y de la conectividad.

27 Sobre los movimientos en la Europa templada ver CHAMPION 2013 y FERNÁNDEZ-GöTZ 2014, 131-141. Sobre el contexto más amplio en el que debería inscribirse el Mediterráneo ver CunLIFFE 2008. Trataré estos temas en otro lugar. 


\section{Migración y movilidad}

La cuestión de la movilidad humana es clave durante toda la Antigüedad pero, por razones prácticas, lo es especialmente en el período romano. La cantidad de objetos que conforman las "diásporas materiales", el número de pecios, el simple tamaño de los barcos, el de las ciudades y las propias dimensiones de las grandes metrópolis, todo ello induce a suponer que los niveles de movilidad en los siglos I a.C. y I d.C. fueron elevados, y que, en términos generales, la movilidad tuvo un carácter diferenciado con respecto a períodos anteriores y posteriores ${ }^{28}$ Cualquiera que sean las limitaciones que establezcamos para la gran época imperial de Roma, éstas serán más rigurosas para períodos anteriores o posteriores. Pero antes de abordar la espinosa cuestión de la cuantificación, merece la pena intentar precisar de forma más clara los tipos de movilidad que podemos encontrar y la dimensión cualitativa del fenómeno.

Un par de artículos escritos por el prehistoriador David Anthony sobre el tema de las migraciones antiguas pueden ser un buen punto de partida. ${ }^{29}$ Migración y movilidad no son sinónimos: en su acepción más común "migración" significa movilidad a larga distancia y quizá implica una reubicación permanente. Pero como se desprende del análisis de Anthony, los dos fenómenos son más cercanos de lo que podría imaginarse a primera vista. Los citados artículos se publicaron en la revista American Anthropology a comienzos de los años noventa y el título del primero, "Migration in Archaeology. The Baby and the bathwater", pone de manifiesto, a un mismo tiempo, el contexto en el que se escribieron y la posición del autor. Uno de los mayores logros de la llamada Nueva Arqueología fue la de presentar una crítica bien sustentada a las explicaciones del cambio cultural como producto exclusivo de movimientos poblacionales. Como parte de un conjunto de ideas caracterizadas por el difusionismo, estas explicaciones fueron vistas con escepticismo, al igual que la idea de que cada pueblo tenía una cultura material particular y que las migraciones podían rastrearse por la dispersión de conjuntos de objetos concretos. Los procesualistas a menudo preferían explicar el cambio cultural como algo que surgía de una evolución social interna, o de respuestas locales a cambios ambientales o a otros estímulos parecidos. Anthony era de la opinión de que esta tendencia había dificultado el análisis de las verdaderas migraciones, hasta el punto de que algunos arqueólogos se negaban incluso a considerar la movilidad humana como un factor posible en procesos tales como la extensión de la agricultura o el origen de las lenguas indoeuropeas, y hacían todo lo posible por restar importancia incluso a migraciones atestiguadas históricamente, como el movimiento de pueblos de lengua celta en el siglo I a.C. o el de los germanos a finales del Imperio romano. ${ }^{30}$

La reacción de Anthony llegó en el momento adecuado; en la actualidad las discusiones sobre las migraciones prehistóricas son mucho más sutiles y tienen en cuenta, junto con la cultura material, un amplio abanico de datos lingüísticos, biológicos

28 Para un intento reciente de describir este fenómeno de forma más precisa ver BowMAN - WILSON 2009 y 2011.

29 Anthony 1990; ID. 1992.

30 Para este contexto ver Adams - VAn Gerven - Levy 1978; Rouse 1986; Collett 1987. 
e históricos. ${ }^{31}$ Sin embargo, sus artículos son útiles para mi propósito porque, con el objetivo de rehabilitar el concepto de migración, llevó a cabo una investigación extensa sobre los estudios modernos de movilidad humana y ofreció algunas ideas sugerentes sobre las formas características que adopta. Su postura puede leerse en el artículo anteriormente citado, en el que establece que la migración es el producto de actividades que emprenden grupos -a menudo unidos por el parentesco-, que normalmente tiene como objetivo un lugar conocido y que, una vez ha comenzado, tiende a desarrollarse a un ritmo regular de intercambio de población. ${ }^{32}$

Las principales conclusiones generales del autor se manifiestan en su exposición sobre "la estructura de las migraciones", que es demasiado larga para reproducirla al completo, pero cuyos puntos básicos pueden resumirse del siguiente modo:

A. Condiciones que favorecen la migración. Se dan cuando hay elementos de atracción a un sitio específico y bien conocido (factores llamada), hay razones para abandonar el hogar (factores de impulso) y el coste de reubicación es asumible. Una variable clave son las normas económicas por las que se rigen los posibles emigrantes y la probabilidad de que sus habilidades sean apreciadas y útiles en el lugar de destino elegido.

B. Migración de corto alcance. "La mayoría de los movimientos migratorios (...) consisten en desplazamientos de corta distancia dentro de una misma área local" y "la mayoría de los movimientos tienen lugar en un ámbito de información que viene representado habitualmente por la interacción de grupos sociales".

C. Migración de larga distancia. "Depende de la transmisión a larga distancia de información relativa a destinos potenciales, y de las rutas de comunicación o tecnologías que reducen los problemas de la distancia".

D. Saltos de rana. "La migración interregional posiblemente se parece más al juego infantil de la pídola que a una ola". Otro término inglés para este tipo de desplazamiento es el de saltation. De nuevo la disponibilidad de información sobre el destino es un factor clave.

E. Flujos migratorios. Los primeros emigrantes establecen caminos y pasan la información de vuelta a emigrantes posteriores, estableciendo así rutas bien definidas. Algunas familias o grupos llegan a actuar como coordinadores, organizando el acomodo y el empleo en el lugar de destino.

F. Migración con retorno. "La mayoría de las grandes oleadas migratorias generan una contra-corriente en dirección al lugar de origen de los emigrantes". Los factores de impulso pueden reducir el regreso de los emigrantes, pero su importancia radica en la información, y a veces riqueza, con la que estos regresan a su lugar de origen.

G. Frecuencia migratoria. "Los emigrantes suelen ser gente que se ha desplazado con anterioridad". Pero cuanto más tiempo pasa el emigrante en su nuevo lugar de destino menos probable es que él o ella se desplace de nuevo. Las comunidades emigrantes suelen generar futuros emigrantes.

31 Una excelente discusión en CHAMPION 2013.

32 Anthony 1990, 895-896. 
H. Demografía de la migración. "El porcentaje de hombres que participan en la oleada migratoria inicial es abrumadoramente superior al de mujeres".

Los argumentos de Anthony presentaban un elevado grado de generalización, ${ }^{33}$ $\mathrm{y}$, como era predecible, fue atacado por los escépticos que no creían en modelos uniformizados de comportamiento humano. No obstante, defendió su posición en su segundo artículo, en el que además clarificó que su objetivo no era desarrollar una tipología de causas de la emigración, sino analizar el tipo de condiciones que hacían que una migración $u$ otra fuera posible o probable. ${ }^{34}$

La mayor parte de la exposición de Anthony es de limitada relevancia para la Antigüedad clásica, aunque algunos aspectos -como la importancia de la contextualización social de la información, la propensión de algunos de los que han emigrado a desplazarse de nuevo, y el modo en que las oleadas migratorias evolucionan con el tiempo- tienen una clara aplicación en el Mediterráneo en época arcaica. Para los historiadores del mundo romano, sin embargo, es precisamente el tono generalizador de la perspectiva de Anthony lo que resulta útil como forma de eludir algunas líneas de discusión sobre la movilidad antigua que están en exceso trilladas. De su presentación es posible extraer algunas preguntas que deberíamos poder responder con los datos disponibles. Para comenzar propongo las siguientes cuestiones sobre la movilidad en el mundo romano: ¿había más movilidad en las distancias cortas?, ¿podemos detectar el desarrollo de oleadas migratorias de larga distancia que saltan determinadas áreas con la finalidad de alcanzar un destino lejano pero bien conocido?, y por último, ¿eran los emigrantes mayoritariamente de género masculino, jóvenes y cualificados? Si la respuesta a estas preguntas es afirmativa, entonces tenemos que comenzar a imaginar la movilidad antigua como el desarrollo de redes frecuentadas por grupos específicos de la sociedad, más que como el tipo de movimiento de Brown que evocan las afirmaciones sobre una conectividad generalizada. ${ }^{35}$

\section{5. ¿Era la movilidad en su mayor parte de corto recorrido?}

La movilidad de corto alcance supone a la vez la reubicación de los individuos o de las familias dentro de un área - por ejemplo de una aldea a otra- y también la movilidad menos permanente de aquellos que buscan trabajo. No siempre es evidente en el momento hasta qué punto será definitivo un desplazamiento. La analogía histórica sugiere claramente que en las sociedades pre-modernas el cambio de residencia podía ser relativamente frecuente. En documentación rural medieval y moderna, Robin Osborne encontró grandes variaciones en el nivel de movilidad de una sociedad a otra, pero también algunas sociedades rurales en las que hasta el 50\% de la población

\footnotetext{
33 Para una visión más ecológica de los modelos generales de movilidad humana ver DiAMOND 1977.

34 Anthony 1992.

35 Para aplicaciones de la network theory al Mediterráneo clásico ver MALKIN 2005; GraHAM 2006; Collar 2007; Constantakopoulou 2007; Malkin - Constantakopoulou - Panagopoulou 2009; Malkin 2011; Collar 2011; Eidinow 2011; MaAs - Ruths 2012; Collar 2013.
} 
de una aldea se resituaba cada generación. ${ }^{36}$ Las disputas familiares y vecinales, la búsqueda de empleo y tierra, los desplazamientos por matrimonio o como reacción a desastres locales y a nuevas oportunidades económicas, todo daba lugar a nuevas reubicaciones. El testimonio papirológico del Egipto romano contiene muchos ejemplos de cambios de residencia y de circulación de comerciantes y artesanos dentro de un nomos o entre nomoi vecinos. ${ }^{37}$ La unificación política del mundo romano casi con total certeza hizo que estos desplazamientos fueran más fáciles, y podemos razonablemente dar por supuesto un pasado de movilidad de corto alcance en la mayor parte del Imperio. Los textos literarios clásicos contienen abundantes testimonios de carácter anecdótico sobre viajes, reales o imaginarios, que han sido con frecuencia analizados. ${ }^{38}$ Pero son los epígrafes y los restos humanos los que suministran más y mejores datos para medir el desplazamiento.

Si bien el tamaño de las muestras totales todavía es muy pequeño, Kristina Killgrove, Tracey Prowse y Hella Eckardt, entre otros, han hecho en los últimos años grandes avances en el estudio de esqueletos gracias al uso del análisis de isótopos básicos. ${ }^{39}$ Aunque parece que una parte significativa de los grupos de tumbas examinados detenidamente pertenecían a individuos que no habían nacido ni crecido en las cercanías, es difícil establecer la importancia estadística de los datos para un cementerio concreto. Otra complicación es que el análisis hecho por Killgrove de isótopos de estroncio en esqueletos antiguos tenía una muestra de 105 individuos, mientras que el análisis de Prowse -basado en isótopos de oxígeno- se sirvió de material dental perteneciente a 61 individuos enterrados en Isola Sacra, la necrópolis del puerto de Ostia, donde esperaríamos, a la luz de otras fuentes como la epigrafía, ${ }^{40}$ un número elevado de emigrantes. No resulta claro hasta qué punto estos resultados pueden generalizarse para el mundo romano. Pero la principal dificultad a la hora de utilizar el análisis de isótopos para medir la movilidad humana es que, mientras que es una buena técnica para identificar individuos que han pasado un período concreto de su vida en lugares diferentes a aquellos donde fueron enterrados, a día de hoy no permite identificar esos lugares de origen. La ratio de isótopos de oxígeno en el agua potable varía de un lugar a otro, pero dentro de un radio corto un valor inusual para una zona determinada puede reflejar al mismo tiempo una migración de largo o de corto alcance y quizás también el uso de agua traída por un acueducto desde una altitud mayor. Estas técnicas progresan rápidamente pero, en la actualidad, todavía no permiten diferenciar una migración de corta distancia de una de larga distancia, como la que documenta la epigrafía. ${ }^{41}$

En efecto, el registro epigráfico con frecuencia recoge el origen de los individuos $\mathrm{y}$, dado que una gran parte de las inscripciones son de carácter funerario, ofrece una buena indicación de los casos individuales de movilidad. ${ }^{42}$ Pero no es fácil usar estas

36 OSBORNE 1991.

37 Braunert 1964; GibBs 2012, especialmente 45-47.

38 CASSON 1974 es difícil de superar a este respecto. Para una descripción imaginaria ver MoRLEY 2003.

39 Killgrove 2010; LeACH et alii 2009; ProwSE et alii 2007; ECKARDT 2010; ECKARDT et alii 2010.

40 BRUUN 2010.

41 BRUUn 2010.

42 Esta discusión se basa en parte en Woolf 2013. 
cifras. En primer lugar, es muy probable que la procedencia de los extranjeros esté sobre-representada en dichas inscripciones, simplemente porque es menos probable que se registren las origines y la ciudadanía municipal de los lugareños cuando mueren cerca de casa. En segundo lugar, es también probable que la dimensión de la movilidad esté infra-representada por la epigrafía funeraria, bien por el simple hecho de que muchas personas regresaron a casa tras su estancia en otro lugar, bien porque fueron homenajeadas allí donde habían vivido y no donde murieron. Aquellos de los que tenemos referencia son los que, desafortunadamente, murieron "en tierra extraña". 43 Por último, muchos habrán muerto en sus civitates de origen, pero en comunidades diferentes a aquellas donde crecieron. De todo ello se sigue que deberíamos esperar más movilidad de la que registran los epitafios, pero que debía de ser una movilidad más local de lo que podría parecer.

Con estas precauciones podemos pasar a los estudios provinciales que han abordado la cuestión. Uno de los primeros fue el de Krier sobre los tréveros, una población bastante viajera. ${ }^{44}$ De los 62 tréveros registrados fuera de su territorio de origen solo tres están atestiguados en el ámbito del Mediterráneo, todos en la ciudad de Roma, y 43 en Germania o la Galia Comata, especialmente en la zona del Rin; los restantes estaban dispersos por las provincias danubianas y Britania. Casualmente, la inmensa mayoría eran soldados y comerciantes, y casi todos hombres. Los estudios de Wierschowski sobre la movilidad regional en el conjunto de las provincias galas muestran que estos patrones estaban bastante generalizados..$^{45}$ Dejando a un lado a soldados y veteranos, el autor documentó 649 casos de movilidad, de los que 500 se localizaban en las propias provincias galas. Estos representaban alrededor del 5\% del total de individuos atestiguados en la epigrafía de las provincias. En el caso de los 149 restantes, la mayor parte se registraba en Hispania o Italia. El estudio de Haley sobre los emigrantes en las provincias hispanas reveló que representaban menos del 5\% de la población atestiguada en el registro epigráfico. ${ }^{46}$ Aún así identificó 715 emigrantes, de los cuales más del $80 \%$ procedían de otras comunidades hispanas, la mayoría soldados, comerciantes y mineros. Las cifras de otras provincias occidentales, aunque han sido recogidas de forma menos sistemática, no sugieren que la Galia o Hispania fueran atípicas.

Las cifras barajadas no respaldan la idea de que la movilidad a larga distancia fuera común en las provincias consideradas. Es cierto que la información hace referencia a regiones continentales en las que las ciudades eran normalmente pequeñas y las relaciones económicas se establecían en distancias relativamente cortas. Sin embargo, los datos epigráficos parecen documentar mayoritariamente formas de movilidad con un alcance relativamente corto, precisamente como sugería David Anthony. La gente se movía de aldeas a pueblos y, de forma ocasional, entre civitates vecinas. La mayoría eran hombres y aquellos que tenían habilidades específicas resultan más visibles que los trabajadores del campo (aunque quizá estos estén infra-representados en la

\footnotetext{
43 Handley 2011.

44 KRIER 1981.

45 WiERSCHOWSKI 1995; ID. 2001.

46 Haley 1991.
} 
documentación epigráfica). Los desplazamientos a larga distancia parecen haber sido infrecuentes.

\section{Flujos migratorios}

Y ¿qué sucede con las oleadas migratorias que avanzan a saltos hacia un destino alejado pero bien conocido, oleadas que evolucionaban con el tiempo en migraciones en dirección contraria y ramificaciones en forma de nuevas rutas migratorias? De hecho, en el mundo romano pueden documentarse una serie de oleadas migratorias, pero se relacionan con grupos bastante especializados, y no con los "pequeños productores" de Horden "que por necesidad a veces tienen que viajar largas distancias para conseguir el sustento". Además, en su mayor parte, y como sucede en muchos movimientos de masas en la Historia, estaban organizados por otros.

El reclutamiento militar captaba individuos de determinadas sociedades y los desplazaba a ciertos destinos según las necesidades del Estado. Es evidente que determinadas legiones recurrían a lugares concretos de reclutamiento y estos podían ser bastante lejanos. Parece que la circulación de individuos se establecía entre las fronteras y el hinterland inmediato más urbanizado, como por ejemplo entre la Galia Narbonense y la zona del Rin y entre África Proconsular y Numidia. La contrapartida de esta circulación era la poco frecuente reubicación de unidades, y el asentamiento de veteranos, pero es evidente que hubo también una emigración de retorno. ${ }^{47}$ Los auxiliares eran también captados con más frecuencia en unas sociedades que en otras -los bátavos y los sirios son ejemplos bien documentados- y algunos, al menos, regresaban a sus lugares de origen después de largos períodos de servicio. ${ }^{48}$ Ciertos emigrantes militares, tanto legionarios como auxiliares, eran reclutados en segmentos de población específicos, definidos por el género, la edad y, en ocasiones, las habilidades.

El tráfico de esclavos generaba también una circulación migratoria a lugares predeterminados, y los comerciantes de esclavos eran selectivos con aquellos que desplazaban, entre los que predominaban sin duda los hombres jóvenes. ${ }^{49} \mathrm{La}$ importancia de las distintas fuentes de esclavos varió con el tiempo. A medida que la red urbana evolucionó y surgieron en ella nuevas metrópolis con la Tetrarquía, podemos predecir que cambiaron también los destinos. Si lo pudiéramos observar de forma más detenida, veríamos el mismo cambio gradual de la circulación que caracterizó el posterior comercio atlántico de esclavos.

Otros flujos migratorios están menos documentados, pero hemos de suponer que se acomodaban a los modelos actuales que maneja la demografía romana. ${ }^{50} \mathrm{El}$ más evidente de todos es el que presupone el denominado "efecto del cementerio urbano", que sostiene que en la mayoría de las sociedades preindustriales, fuesen del tamaño

47 Forni 1953; KePPIE 1983.

48 Ver HAYNES 2013.

49 Harris 1980; SCHEIdel 1997; Harris 1999. Para un debate en profundidad ver Harris 2011.

50 PARKIn 1992; ScheIdel 2001; ID. 2007; ScheIdel (ed.), 2001. 
que fuesen, la mortalidad fue siempre más elevada que la natalidad y que, en consecuencia, las ciudades tan grandes como la antigua Roma dependieron de inmigración de algún tipo para mantener el volumen de su población. ${ }^{51}$ Esta visión -al menos en su forma más simple y general- ha recibido recientemente una continua crítica. Saskia Hin ha mostrado hasta qué punto dicha visión descansa en una analogía con lugares y períodos mejor documentados y, aunque concluye que la ciudad de Roma probablemente necesitó algo de inmigración, se pregunta por la dimensión real del fenómeno. ${ }^{52}$ Por su parte, Elio Lo Cascio ha señalado que la demografía de las ciudades modernas era bastante variable, cuestionando algunos de los argumentos tradicionales y más recientes sobre el carácter especialmente insalubre de la ciudad de Roma. ${ }^{53}$ Aunque el debate continúa, hay un amplio consenso en torno al hecho de que Roma y otras grandes ciudades de la Antigüedad clásica estaban densamente pobladas, así como que amplias capas de la población vivían en condiciones de pobreza e inseguridad como resultado de su insuficiente alimentación y de la cantidad de enfermedades endémicas, que hacían de ellas el blanco de epidemias. ${ }^{54}$ Por ello, es muy probable que los testimonios literarios sobre la inmigración reflejen una verdadera dependencia demográfica de la llegada de emigrantes, incluso aunque sea con carácter estacional. Muchos de esos emigrantes pudieron sufrir una mortalidad más elevada que los residentes de larga duración, y parte de ellos serían emigrantes involuntarios, es decir esclavos, pero el resto procedería, con mucha probabilidad, de pequeñas ciudades y aldeas de Italia y de las provincias cercanas, como ha sucedido tradicionalmente. ${ }^{55}$

La mayoría de los debates terminan aquí, una vez que han establecido la relación entre urbanización y hinterland rural, o entre ciudades grandes y pequeñas. Pero es posible también, como experimento, considerar la población global de todo el Mediterráneo. Si es correcto que no hubo una inmigración regular significativa desde más allá de las fronteras imperiales, y que el crecimiento demográfico dentro del Imperio fue quizá del 0,1\% anual, podemos comenzar a intuir la dinámica interna del sistema en forma de flujos migratorios desde áreas donde la fertilidad superaba la mortalidad a otras donde se daba la situación contraria. Sin duda, la esclavitud explica parte de este desplazamiento, aunque no hay razón para creer que todas las regiones con alta fertilidad fueron lugares de esclavización a gran escala: el norte de Italia, por ejemplo, cuya población estaba íntegramente compuesta por ciudadanos romanos desde comienzos de siglo I a.C., no es muy probable que fuera un lugar de esclavización. Ciertamente algunos flujos migratorios fueron estacionales, relacionados con la variable demanda de mano de obra de la agricultura intensiva (lo que incluye la viticultura y la producción de aceite) y de las industrias en la ciudad (construcciones, por ejemplo, pero también trabajo en los puertos, que eran mucho más activos en el

51 Entre otros Hopkins 1978; ID.1978a; Morley 1996; SCheidel 1997; ID. 2004; PAine - Storey 2006; SCHEIDEL 2007; DE LigT - NoRTHWOOD 2008; ERDKAMP 2008.

52 HiN 2013.

53 LO CASCIO 2006.

54 SAllares 2002; SCHeIDEl 2003.

55 Brunt 1971; Hopkins 1978; Morley 1996. Para un contexto itálico más amplio Morley 1997; PATTERSON 2006. 
período de navegación que en los meses de invierno). ${ }^{56}$ Flujos migratorios análogos, ya sean permanentes o estacionales, debieron de generarse en otras grandes ciudades como Cartago, Alejandría, Antioquía de Siria y Constantinopla. Estos mismos centros atraían, por supuesto, a comerciantes, algunos de los cuales frecuentaban las rutas regulares de carácter anual, como las del grano que iban de Alejandría y Cartago a Roma. Es también probable, aunque difícil de documentar, que la fragmentación ecológica del mundo mediterráneo y las alteraciones locales entre la sobreabundancia y la escasez (siguiendo la terminología de Horden y Purcell) generaran un tráfico hacia los grandes centros. Si bien la noción de una conectividad generalizada puede llevarnos a imaginar, en principio, que los campesinos con excedentes inesperados intentarían contactar directamente con los lugares que estuvieran sufriendo una escasez inusual, la circulación de la información en el Mediterráneo antiguo deja en evidencia que esta habría sido una estrategia arriesgada que habría requerido mucho tiempo: sería más seguro para aquellos que tenían excedentes llevarlos a un gran puerto y para aquellos que necesitaban suministros adicionales ir a esos mismos puertos. Y dado que en algunos lugares se producían excedentes de manera habitual, algunas de estas rutas, al igual que los núcleos de población, se habrían fijado con el tiempo. Este tipo de movilidad también se parece a la noción de flujo de migración según la terminología de Anthony.

El reclutamiento y asentamiento militares, el comercio de esclavos y la demanda de mano de obra de las metrópolis antiguas y de los propietarios de villae, la desproporción entre fertilidad y mortalidad a lo largo del Mediterráneo, así como el comercio de productos básicos - que generaba otros desequilibrios-, todo ello combinado propiciaba una red de flujo migratorio cambiante. Esta circulación de población era esencial para mantener determinadas estructuras económicas y políticas a las que estaban vinculadas las élites antiguas, entre ellas las villas agrícolas, las residencias urbanas y el mantenimiento del Estado imperial. Por estas razones las élites antiguas forzaban ciertos desplazamientos e incentivaban y facilitaban otros. Esta variada movilidad a larga distancia ponía en contacto poblaciones que en su mayor parte se movían en distancias muy cortas durante su vida, aunque no llegaban a formar comunidades autárquicas y aisladas. En lugar de una movilidad generalizada, propongo la idea de que el mundo antiguo estuvo caracterizado por una minoría de viajeros - que iban y venían siguiendo unos flujos de migración fijos- y una mayoría de residentes que habitaban pequeños mundos, aunque fueran conscientes de la existencia de un marco geográfico mayor al que estaban conectados a través de los visitantes y al que se podían dirigir de forma ocasional, unas veces por un corto período de tiempo y otras para siempre.

56 Una excelente exposición en ERDKAMP 2008, 424-433. 


\section{Una revisión de la movilidad a larga distancia}

Entonces, ¿cuánta gente se movía? Los estudios epigráficos citados anteriormente han arrojado unas cifras muy bajas de individuos atestiguados fuera de sus comunidades de origen, del orden del 5\%. La cifra dista de ser segura por las razones ya mencionadas pero, en cualquier caso, no es muy compatible con unos niveles elevados de movilidad a larga distancia. Casi todos los testimonios epigráficos pueden explicarse por viajes de corto recorrido dentro de una región realizados más por residentes que por viajeros. Una aproximación diferente a la cuestión de la movilidad a larga distancia supone preguntar por la capacidad de transporte que tenía el sistema de comunicaciones antiguo. Gran parte de la investigación reciente aborda este aspecto. ${ }^{57} \mathrm{Mi}$ intención en la parte final de este artículo es plantear algunos parámetros generales, es decir, establecer los límites de lo que resultaba factible. Para ello comenzaré con una par de suposiciones básicas.

Me concentraré especialmente en los viajes marítimos. Comprendo que los viajes terrestres eran importantes, pero en su mayor parte lo eran para las comunicaciones locales (es decir, de la ciudad al campo y entre ciudades vecinas). Esto concuerda con la importancia que los agrónomos dan al transporte por tierra, y con la necesidad lógica de que los centros de consumo estén conectados con el hinterland rural. ${ }^{58} \mathrm{Co}$ lin Adams está en lo cierto al afirmar que tenemos que ir más allá de la comparación en el coste de los sistemas de transporte marítimo, fluvial y terrestre y preguntarnos de qué forma se integraban los distintos tipos de transporte. ${ }^{59}$ Siempre que podemos seguir un viaje largo con detalle -por ejemplo, el de Plinio a su provincia o el de Teófanes de Egipto a Antioquía- es común encontrar el uso de diferentes métodos de transporte en distintas etapas. ${ }^{60}$

A la información que Adams ha extraído de los papiros egipcios hay que añadir los recientes estudios dedicados a los sistemas de transporte en la Europa romana. Grupos especializados como el de los utricularii trabajaban junto con nautae y navicularii para distribuir productos que llegaban por transporte marítimo y fluvial hasta localidades del interior, mientras que el comercio regular a través de las rutas transalpinas lo organizaban, de un modo que todavía no es por completo claro, ciertos corpora de mercaderes. ${ }^{61}$ En realidad, se ha sobredimensionado el alto precio del transporte terrestre y la verdad es que a menudo no había otra alternativa disponible. ${ }^{62}$ No obstante, es cierto que los pocos relatos de viajes largos por tierra de que

57 Adams - Laurence 2001; Adams 2007; Adams - Roy 2007; Malkin - Constantakopoulou Panagopoulou 2009; Talbert 2010; Alcock - Bodel - Talbert 2012.

58 LAURENCE 1999.

59 ADAMS 2007.

60 Plin., Ep. 10.15-17: por mar a Éfeso, por tierra a Pérgamo, luego mediante cabotaje a Cízico y de nuevo por tierra hasta Apolonia y Prusa. En el caso de Teófanes el viaje supone el descenso del Nilo en barco, y luego por vía terrestre hasta Antioquía, en su mayor parte en carro (raeda), pero posiblemente a caballo en el último tramo. Matthews 2006. Los ejemplos se pueden multiplicar fácilmente.

61 Para los utricularii ver LiU 2009, 136-138, quien se basa en KNeIssL 1981; Deman 2002. Para el splendidissimum corpus mercatorum Cisalpinorum et Transalpinorum ver HITCHNER 2012, quien cita a WALSER 1989; ID. 1991.

62 LAURENCE 1999. 
disponemos -los más detallados son los de los primeros peregrinos a Tierra Santa y los del ya citado propietario egipcio Teófanes, todos del siglo IV d.C.- sugieren que tales viajes eran caros, difíciles y lentos, incluso para aquellos que tenían diplomata que les permitían usar la vehiculatio y las mansiones imperiales. ${ }^{63}$ Por ello, dejando a un lado el caso especial del movimiento de tropas, debemos suponer que la mayor parte de los viajes largos se hacían por mar, y también que el cabotaje atendía sobre todo las necesidades locales, aunque a veces se integrara en redes comerciales más amplias como medio para distribuir algunas manufacturas y, quizá, acercar productos en pequeñas cantidades a mercados más grandes.

Sugiero, además, que el viaje marítimo suponía un cuello de botella en el sistema, un punto de esta red integrada de transporte en el que ampliar la capacidad de transporte requería una gran inversión. Entonces, ¿qué viajes marítimos se emprendían? Se han presentado una serie de cálculos para el número de viajes realizados anualmente con barcos de diferente tamaño y Dominic Rathbone ha revisado algunos de los más importantes. ${ }^{64}$ Así, analiza las estimaciones de Tchernia -unos 800 barcos de 150-350 toneladas métricas cada uno, que harían dos o tres viajes de ida y vuelta cada año- y sostiene que los navíos eran, en su mayor parte, más pequeños, lo que lleva a pensar en unos 1500 navíos de entre 60 y 330 toneladas; del mismo modo, considera que tres viajes de ida y vuelta dentro de una misma temporada marítima resultan inverosímiles salvo para las rutas más pequeñas. El objetivo de Rathbone es enfatizar la gran escala acumulativa del comercio marítimo, que según él creaba un efecto de red basado en un número elevado de viajes en barcos, en su mayoría, de pequeñas dimensiones. ${ }^{65}$ También las actas de un congreso recientemente editadas por Harris e Iara sobre la tecnología marítima destacan el predominio de los barcos pequeños, con el argumento de que los grandes, de unas 300 toneladas, están sobrerepresentados por los testimonios de pecios y serían exageradamente costosos para muchos transportistas. ${ }^{66}$

Hasta aquí la argumentación parece apuntar a un tráfico denso, sobre todo en los momentos centrales de la temporada de navegación, entre mayo y septiembre. No obstante, esto puede no traducirse en una elevada capacidad de transporte de pasajeros. Los navíos más grandes atestiguados en las fuentes literarias parecen haber sido especialmente diseñados para el transporte a gran escala de alimentos, como los barcos de grano que cruzaban de Alejandría y Cartago al puerto de Ostia. Algunos, como los efímeros navíos de dolia de época augustea, definitivamente tenían poco espacio libre. Un pequeño número de navíos de grandes dimensiones se utilizaba para el transporte de piedra ${ }^{67} \mathrm{y}$, aparentemente, había navíos especiales para los animales. Pero carecemos de testimonios sobre barcos específicos para pasajeros del tipo que posteriormente se usará para el asentamiento, voluntario o involuntario, de gente en

63 Casson 1974; Wilkinson 1982; Hunt 1982; Matthews 2006. Sobre el llamado cursus publicus: Mitchell 1976; ID. 1982; Kolb 2000; ID. 2001. Para una visión de conjunto sobre la institución ver TALBERT 2012.

64 Rathbone 2003.

65 RATHBone 2009.

66 HARRIS - IARA 2011.

67 TCHERNIA 2011. 
el Nuevo Mundo. La mayor parte de los relatos de viajes sitúan a los pasajeros instalados en navíos comerciales. ${ }^{68}$ Lo más probable es que los navíos que hacían rutas de larga distancia no pudieran llevar-si es que podían albergar alguno- más de una docena de pasajeros.

Nos ha llegado un número reducido de relatos de naufragios. Flavio Josefo describe en su Vida (3) que, en su viaje a Roma, el barco en el que se desplazaba se hundió en el Adriático con unos 600 pasajeros a bordo, de los cuales solo 80 sobrevivieron y fueron rescatados por un navío de Cirene. Más conocido aún es el relato bíblico de Hechos 27.37 sobre el naufragio de un barco enorme que transportaba grano cada año desde Alejandría a Roma, pasando aparentemente por Asia Menor y atravesando el Egeo antes de girar en Malea para franquear después el estrecho de Mesina. En este caso llevaba, supuestamente, 276 pasajeros a bordo. Estos navíos eran, según Filón, el medio de transporte preferido para unir Roma y Alejandría, sin duda porque su gran tamaño permitía una mayor comodidad. ${ }^{69} \mathrm{El}$ último relato es la carta cuarta de Sinesio en la que se describe el naufragio de un barco que había partido de Alejandría con dirección a Cirene; además del cargamento, llevaba 12 tripulantes y unos 50 pasajeros. Hacer un cálculo a partir de anécdotas como estas es extraordinariamente difícil, pero podría dar una orientación sobre las distintas posibilidades.

Si mil navíos hacían dos viajes de ida y vuelta anualmente llevando cada uno una media de treinta pasajeros, eso daría una cifra total de 60.000 trayectos de larga distancia por año en el Mediterráneo. Si es así, significaría que solo una persona de cada mil, de una población total de 60 millones, haría un viaje de larga distancia en un año cualquiera. Dicho de otra manera, en un Imperio de aproximadamente unas mil ciudades, solo el equivalente a la población de una ciudad de tamaño medio hacía un viaje por mar al año. No hay forma de eludir el carácter provisional y especulativo de estos cálculos, pero al menos proporcionan algunos parámetros útiles para evaluar las afirmaciones a favor de una elevada movilidad, y no son muy diferentes de lo que los testimonios epigráficos ofrecen.

\section{Viajeros y residentes}

Los súbditos de los emperadores romanos no pasaban su vida en casa o aislados, ni eran autosuficientes según propugna la ideología de la autarquía. La movilidad y conectividad humanas son conceptos clave a la hora de comprender la evolución del Mediterráneo como una zona de poblamiento que, en determinados momentos, albergó un puñado de grandes ciudades y algunos grandes Estados. Pero es fundamental mantener el sentido de la perspectiva. Los prehistoriadores que han estudiado el tema se han mostrado cautelosos, apuntando las limitaciones de los viajes y su pequeña escala, pero también su enorme importancia. ${ }^{70}$ Desde mediados del tercer milenio se hicieron esfuerzos ímprobos para mejorar la tecnología marítima y las técnicas de na-

68 Pomey 1997.

69 Filón, in Flaccum 25-27, presenta a Gayo recomendando esta ruta a Herodes.

70 BROODBANK 2013. 
vegación, y tales esfuerzos continuaron a lo largo del período romano, ${ }^{71}$ lo que indica que, en realidad, la conectividad no estaba asegurada en la Antigüedad.

En el período romano la movilidad se desarrolló, en gran medida, en distancias bastante cortas. La mayor parte de la población estuvo constituida por residentes estables (es decir que se mantenían en, o cerca de casa) y no por viajeros (es decir, que no recorrían grandes distancias). La movilidad a larga distancia fue infrecuente e involucró a una pequeña parte de la población. El grupo de los viajeros era aleatorio con respecto a la población general. Como ya he defendido en otro lugar, las mujeres prácticamente no se movían a no ser que lo hicieran en compañía de sus familiares masculinos o sus dueños, y a menudo familiares y dueños se desplazaban sin ellas. Por lo que respecta a los varones, raras veces se desplazaron a larga distancia, quizá solo una vez o dos en sus vidas, llevados por otros. Para la mayoría la vida tenía un horizonte reducido.

Merece la pena destacar, sin embargo, que aunque solo una proporción pequeña de la población se embarcara en una migración o viaje de largo recorrido, su desplazamiento podía tener importantes efectos. Muchos testimonios literarios hablan de los desplazamientos de individuos de alto estatus -embajadores y gobernadores, príncipes y sofistas por igual-y un porcentaje elevado de epígrafes está relacionado con comerciantes y artesanos. Incluso pequeños grupos de individuos como estos pudieron generar una conectividad considerable a lo largo del Imperio y más allá de él. ${ }^{72}$ Uno de los fundadores del Social Network Analysis, Mark Granovettar, señalaba que los débiles lazos que conectan dos o más redes locales densamente trabadas tienen una especial importancia ya que son precisamente esos lazos débiles los que proporcionan información previamente no compartida por la comunidad. ${ }^{73}$ Esta perspectiva se ha aplicado también para explicar el cambio religioso en el mundo romano. ${ }^{74}$ Partiendo de un punto inicial diferente, Bruce Frier sostiene, en una de las mejores síntesis sobre demografía romana, que el equilibrio entre los índices de mortalidad $\mathrm{y}$ de fertilidad en las sociedades antiguas era tan precario que incluso la migración más modesta podía tener grandes consecuencias. ${ }^{75}$ Así pues, no es necesario que la movilidad sea elevada o muy ubicua para que tenga efectos significativos. Dicho de otro modo, un elevado grado de conectividad no requiere de un elevado grado de movilidad.

\section{Bibliografía}

AdAms, C. (2007): Land transport in Roman Egypt. A study of economics and administration in a Roman province, Oxford (http://dx.doi.org/10.1093/acprof:oso/9780199203970.001.0001). Adams, C. - Laurence, R. (EDS.), (2001): Travel and Geography in the Roman Empire, London.

71 Broodbank 2006; ID. 2010; HARRIS - IARA 2011.

72 Matthews 1989.

73 GranOVETTER 1973.

74 Collar 2007, ID. 2011; ID. 2013; Price 2012.

75 FrIER 2000, 808-811. 
Adams, C. - Roy, J. (EDS.), (2007): Travel, Geography and Culture in Ancient Greece, Egypt and the Near East (=Leicester-Nottingham Studies in Ancient Society 10), Oxford.

Adams, W. Y. - Van Gerven, D. P. - Levy, R. S. (1978): "The Retreat from Migrationism", Annual Review of Anthropology 7, $483-532$ (http://dx.doi.org/10.1146/annurev. an.07.100178.002411).

Alcock, S. E. - Bodel, J. - TAlbert, R. J. A. (EDS.), (2012): Highways, Byways, and Road Systems in the Pre-Modern World (=Ancient World, Comparative Histories 5), Malden (http://dx.doi.org/10.1002/9781118244326).

AnThony, D. W.

(1990): "Migration in Archeology. The Baby and the bathwater", American Anthropologist 92/4, 895-914 (http://dx.doi.org/10.1525/aa.1990.92.4.02a00030).

(1992): "The Bath refilled. Migration in Archeology again", American Anthropologist 94/1, 174-176 (http://dx.doi.org/10.1525/aa.1992.94.1.02a00140).

Bickerman, E. (1952): “Origines Gentium”, Classical Philology 47, 65-81 (http://dx.doi. org/10.1086/363470).

Blake, E. (2008): "The Mycenaeans in Italy. A Minimalist Position”, Papers of the British School at Rome 76, 1-34 (http://dx.doi.org/10.1017/S0068246200000398).

Bowman, A. - Wilson, A. (EDS.)

(2009): Quantifying the Roman Economy. Methods and problems, Oxford (http://dx.doi. org/10.1093/acprof:oso/9780199562596.001.0001).

(2011): Settlement, Urbanization, and Population, Oxford (http://dx.doi.org/10.1093/acpr of:oso/9780199602353.001.0001).

Braunert, H. (1964): Die Binnenwanderung. Studien zur Sozialgeschichte Ägyptens in des Ptolemäer- und Kaiserzeit (=Bonner historische Forschungen 26), Bonn.

Bresson, A. (2005): “Ecology and Beyond. The Mediterranean Paradigm”, [en] Harris (ed.), 2005, 94-114.

Broodbank, C.

(2006): "The Origins and Early Development of Mediterranean Maritime Activity", Journal of Mediterranean Archaeology 19/2, 199-230 (http://dx.doi.org/10.1558//jmea.2006. v19i2.199).

(2010): "Ships a-sail from over the rim of the sea. Voyaging, sailing and the making of Mediterranean societies c. 3500-800 BC.", [en] A. J. Anderson - J. H. Barrett - K. V. Boyle (eds.), The Global Origins and Development of Seafaring, Cambridge, 249-264.

(2013): The Making of the Middle Sea. A history of the Mediterranean from the beginning to the emergence of the classical world, New York-Oxford.

Brunt, P. A. (1971): Italian Manpower 225 B.C. - A.D. 14, Oxford.

BruUn, CH. (2010): "Water, oxygen isotopes and immigration to Ostia-Portus", Journal of Roman Archaeology 23, 109-132 (http://dx.doi.org/10.1017/S1047759400002324).

Casson, L. (1974): Travel in the Ancient World, Baltimore-London.

Champion, T. C. (2013): "Protohistoric European Migrations", [en] Ness (ed.), 2013, 24632468 (http://doi.org./10.1002/9781444351071.wbeghm425).

Collar, A.

(2007): "Network Theory and Religious Innovation", Mediterranean Historical Review 22/2, 149-162 (http://dx.doi.org/10.1080/09518960701539372). 
(2011): "Military Networks and the Cult of Jupiter Dolichenus", [en] E. Winter (ed.), Von Kummuh nach Telouch. Historische und archäologische Untersuchungen in Kommagene. Dolichener und Kommagenische Forschungen 4., Bonn, 217-245.

(2013): Religious Networks in the Roman Empire. The spread of new ideas, Cambridge.

Collett, D. (1987): “A contribution to the study of migrations in the archaeological record: the Ngoni and Kokolo migrations as a case study", [en] I. Hodder (ed.), Archaeology as Long-term history, Cambridge, 105-116.

Constantakopoulou, CH. (2007): The Dance of the Islands. Insularity, networks, the Athenian Empire and the Aegean World, Oxford (http://dx.doi.org/10.1093/acprof:o so/9780199215959.001.0001).

Cunliffe, B. W. (2008): Europe between the Oceans. Themes and variations, 9000 BC-AD 1000, New Haven-London.

De Ligt, L. - Northwood, S. (eds.), (2008): People, Land and Politics. Demographic developments and the transformation of Roman Italy 300 BC - AD 14 (=Mnemosyne Supplements 303), Leiden.

Deman, A. (2002): “Avec les utriculaires sur les sentiers muletiers de la Gaule romaine", Cahiers du Centre Gustave Glotz 13, 233-246 (http://dx.doi.org/10.3406/ccgg.2002.1567).

Diamond, J. M. (1977): “Colonization cycles in man and beast”, World Archaeology 8/3, 249261 (http://dx.doi.org/10.1080/00438243.1977.9979671).

Dommelen, P. van - Knapp, B. A. (EDs.), (2010): Material Connections in the Ancient Mediterranean. Mobility, Materiality and Identity, London-New York.

Earle, T. - Gamble, C. - Poinar, H. (2011): "Migration”, [en] A. Shryock - D. L. Smail (eds.), Deep History. The Architecture of Past and Present, Berkeley-Los Angeles-London, 191-218.

ECKARDT, H. (ED.), (2010): Roman Diasporas. Archaeological approaches to mobility and diversity in the Roman empire (=Journal of Roman Archaeology, Supplement 78), Portsmouth.

Eckardt, H. - Chenery, C. - Leach, S. - Lewis, M. - Müldner, G. - Nimmo, E. (2010): “A long way from home: diaspora communities in Roman Britain", [en] Eckardt (ed.), 2010, 99-130.

Edwards, C. - Woolf, G. (EDS.), (2003): Rome the Cosmopolis, New York.

EIDINOW, E. (2011): "Networks and Narratives. A model for ancient Greek religion", Kernos 24, 9-38 (http://dx.doi.org/10.4000/kernos.1925).

Elsner, J. - Rutherford, I. (EDS.), (2005): Pilgrimage in Graeco-Roman and early Christian Antiquity. Seeing the gods, Oxford.

ERDKAMP, P. (2008): "Mobility and migration in Italy in the second century BC.”, [en] de Ligt - Northwood (eds.), 2008, 417-449.

Fentress, J. - Fentress, E. (2001): "Review Article. The Hole in the Doughnut", Past and Present 173, 203-219.

Fernández-Götz, M. (2014): Identity and Power. The transformation of Iron Age Societies in Northeast Gaul (=Amsterdam Archaeological Studies 21), Amsterdam.

Finley, M. I. (1973): The Ancient Economy (=Sather Classical Lectures 43), Berkeley.

Forni, G. (1953): Il reclutamento delle legioni da Augusto a Diocleziano, Milano. 
Frier, B. W. (2000): “Demography”, [en] A. Bowman - P. Garnsey - D. Rathbone (eds.), Cambridge Ancient History, volume XI. The High Empire, A.D. 70-192, Cambridge, 787816 (http://dx.doi.org/10.1017/CHOL9780521263351.028).

GARnsey, P. (1988): Famine and Food Supply in the Greco-Roman World. Responses to risk and crisis, Cambridge (http://dx.doi.org/10.1017/cbo9780511583827).

GibBs, M. (2012): "Manufacture, trade and the economy", [en] Ch. Riggs (ed.), The Oxford Handbook of Roman Egypt, Oxford, 38 -55 (http://dx.doi.org/10.1093/oxford$\mathrm{hb} / 9780199571451.013 .0004)$.

Graham, S. (2006): "Networks, Agent-Based Models and the Antonine Itineraries. Implications for Roman Archaeology", Journal of Mediterranean Archaeology 19/1, 45-64 (http:// dx.doi.org/10.1558/jmea.2006.19.1.45).

Granovetter, M. S. (1973): “The Strength of Weak Ties”, American Journal of Sociology 78/6, 1360-1380 (http://dx.doi.org/10.1086/225469).

Haley, E. W. (1991): Migration and Economy in Roman Imperial Spain (=Aurea Saecula 5), Barcelona.

Halstead, P. - O'Shea, J. (1982): “A friend in need is a friend indeed. Social storage and the origins of social ranking”, [en] C. Renfrew - St. Shennan (eds.), Ranking, Resources and Exchange. Aspects of the archaeology of early European society, Cambridge, 92-99.

Handley, M. (2011): Dying on foreign shores. Travel and mobility in the late antique west (=Journal of Roman Archaeology, Supplement 86), Portsmouth.

HARRIS, W. V.

(1980): “Towards a study of the Roman slave trade", [en] J. H. D'Arms - E. C. Kopff (eds.), The Seaborne Commerce of Ancient Rome (=Memoirs of the American Academy in Rom 36), Rome, 117-140 (http://dx.doi.org/10.2307/4238700).

(1999): "Demography, geography and the sources of Roman slaves", Journal of Roman Studies 89, $62-75$ (http://dx.doi.org/10.2307/300734).

(2005): "The Mediterranean and Ancient History", [en] Harris (ed.), 2005, 1-42.

(2011): The Roman Imperial Economy. Twelve essays, Oxford.

(2013): The Ancient Mediterranean Environment between Science and History (=Columbia Studies in the Classical Tradition 39), Leiden-Boston.

HARRIS, W. V. (ED.), (2005): Rethinking the Mediterranean, Oxford.

Harris, W. V. - IARA, K. (EDS.), (2011): Maritime Technology in the Ancient Economy. Shipdesign and navigation (=Journal of Roman Archaeology, Supplement 94), Portsmouth.

Haynes, I. (2013): Blood of the Provinces. The Roman Auxilia and the making of provincial society from Augustus to Diocletian, Oxford.

Hin, S. (2013): The Demography of Roman Italy. Population Dynamics in an Ancient Conquest Society 201 BCE-14 CE, Cambridge (http://dx.doi.org/10.1093/OBO/97801953896610208).

Hitchner, R. B. (2012): "Roads, Integration, Connectivity and Economic Performance in the Roman Empire", [en] Alcock - Bodel - Talbert (eds.), 2012, 222-234 (http://dx.doi. org/10.1002/9781118244326.ch11).

HopKINS, K.

(1978): Conquerors and Slaves (=Sociological Studies in Roman History 1), Cambridge. 
(1978a): "Economic Growth and Towns in Classical Antiquity", [en] Ph. Abrams - E. A Wrigley (eds.), Towns in Societies. Essays in economic history and historical sociology, Cambridge, 35-77.

(1980): "Taxes and Trade in the Roman empire (200 BC-AD 400)", Journal of Roman Studies 70, 101-125 (http://dx.doi.org./10.2307/299558).

(1995/6): "Rome, taxes, rents and trade", Kodai 6/7, 41-75.

(2000): "Rent, taxes, trade and the City of Rome", [en] E. Lo Cascio (ed.), Mercati permanenti e mercato periodi nel mondo romano. Atti degli Incontri capresi di storia dell'economia antica (Capri 13-15 ottobre 1997), Bari, 253-267.

Horden, P. (2005): "Travel sickness. Medicine and mobility in the Mediterranean from Antiquity to the Renaissance" [en] Harris (ed.), 2005, 179-199.

Horden, P. - Purcell, N. (2000): The Corrupting Sea. A Study of Mediterranean history, Oxford.

Hunt, E. (1982): Holy Land Pilgrimage in the Later Roman Empire AD 312-460, Oxford.

KeppIE, L. J. F. (1983): Colonisation and Veteran Settlement in Italy 47-14 BC, London.

KILlgrove, K. (2010): "Identifying immigrants to Imperial Rome using strontium isotope analysis", [en] Eckardt (ed.), 2010, 157-174.

KNEISSL, P. (1981): "Die Utricularii. Ihr Rolle im gallo-römischen Transportwesen und Weinhandel”, Bonner Jahrbücher 181, 169-203.

Kolb, A.

(2000): Transport und Nachrichtentransfer im Römischen Reich (=Klio. Beiträge zur alten Geschichte. Beihefte, neue Folge, Bd. 2), Berlin.

(2001): "Transport and Communication in the Roman State. The cursus publicus", [en] Adams - Laurence (eds.), 2001, 95-105.

KrIER, J. (1981): Die Treverer außerhalb ihrer Civitas. Mobilität und Aufstieg (=Trierer Zeitschrift Beihefte 5), Trier.

Lane Fox, R. (2008): Travelling Heroes. Greeks and their myths in the epic age of Homer, London.

LAUREnCE, R. (1999): The Roads of Roman Italy. Mobility and cultural change, London.

Leach, St. - Lewis, M. - Chenery, C. - Müldner, G. - EcKardt, H. (2009): "Migration and diversity in Roman Britain. A multidisciplinary approach to the identification of immigrants in Roman York, England", American Journal of Physical Anthropology 140, 546561 (http://dx.doi.org/10.1002/ajpa.21104).

LiU, J. (2009): Collegia Centonariorum. The guilds of textile dealers in the Roman West (=Columbia Studies in the Classical Tradition 34), Leiden-Boston.

Lo CASCIO, E. (2006): "Did the population of imperial Rome reproduce itself?", [en] Storey (ed.), 2006, 52-68.

MaAs, M. - Ruths, D. (2012): "Road Connectivity and the Structure of Ancient Empires. A case study from late antiquity", [en] Alcock - Bodel - Talbert (eds.), 2012, 255-264 (http:// dx.doi.org/10.1002/9781118244326.ch13).

MALKIN, I.

(2005): "Networks and the emergence of Greek identity", [en] Malkin (ed.), 2005, 56-74.

(2011): A Small Greek World. Networks in the Ancient Mediterranean, New York. 
Malkin, I. (ED.), (2005): Mediterranean Paradigms and Classical Antiquity, London-New York.

Malkin, I. - Constantakopoulou, Ch. - Panagopoulou, K. (EDs.), (2009): Greek and Roman Networks in the Mediterranean, London-New York.

Manning, S. W. - Hulin, L. (2005): "Maritime commerce and geographies of mobility in the late Bronze Age of the eastern Mediterranean: problematizations", [en] E. Blake - A. B. Knapp (eds.), The Archaeology of Mediterranean Prehistory, Malden-Oxford-Carlton, 270-302 (http://dx.doi.org/10.1002/9780470773536.ch11).

Matthews, J. F.

(1989): "Hostages, philosophers, pilgrims, and the diffusion of ideas in the late Roman Mediterranean and Near East", [en] F. M. Clover - R. S. Humphreys (eds.), Tradition and Innovation in Late Antiquity, Madison, 29-49.

(2006): The journey of Theophanes. Travel, business, and daily life in the Roman east, New Haven.

MitChell, St.

(1976): "Requisitioned Transport in the Roman Empire. A New Inscription from Pisidia", Journal of Roman Studies 66, 106-131 (http://dx.doi.org/10.2307/299783).

(1982): "The Requisitioning Edict of Sex. Sotidius Strabo Libuscidianus", Zeitschrift für Papyrologie und Epigraphik 45, 99-100.

Moatti, C.

(2006): "Translation, Migration, and Communication in the Roman Empire. Three aspects of movement in history", Classical Antiquity 25/1, 109-140 (http://dx.doi.org/10.1525/ ca.2006.25.1.109).

(2013): "Immigration and Cosmopolitanization", [en] P. Erdkamp (ed.), Cambridge Companion to Ancient Rome, Cambridge, 77-92 (http://dx.doi.org/10.1017/CCO9781139025973).

MoATti, C. (DIR.), (2004): La mobilité des personnes en Méditerranée de l'antiquité à l'époque moderne. Procédures de contrôle et documents d'identification (=Collection de l'Ecole française de Rome 341), Roma.

MoAtti, C. - Kaiser, W. (2007): Gens de passage en Méditerranée de l'Antiquité à l'époque moderne. Procédures de contrôle et d'identification, Paris.

MoRley, N.

(1996): Metropolis and Hinterland. The city of Rome and the Italian economy 200 B.C. A.D.200, Cambridge (http://dx.doi.org/10.1017/CBO9780511518584).

(1997): "Cities in context. Urban systems in Roman Italy", [en] H. Parkins (ed.), Roman Urbanism. Beyond the consumer city, London, 42-58.

(2003): "Migration and the metropolis", [en] Edwards - Woolf (eds.), 2003, 147-157.

Ness, I. (ED.), (2013): Encyclopaedia of Global Human Migration, Malden-Oxford.

OSBORNE, R.

(1991): "The potential mobility of human populations", Oxford Journal of Archaeology 10/2, 231-252 (http://dx.doi.org/10.1111/j.1468-0092.1991.tb00015.x).

(2009): Greece in the Making 1200-479 BC, London (second edition).

Paine, R. R. - Storey, G. R. (2006): "Epidemics, age at death, and mortality in Ancient Rome", [en] Storey (ed.), 2006, 69-85.

PARKIN, T. (1992): Demography and Roman Society, Baltimore-London. 
PAtterson, J. R. (2006): Landscapes and Cities. Rural settlement and civic transformation in early imperial Italy, Oxford.

Pomey, P. (DIR.), (1997): La navigation dans l'antiquité, Aix-en-Provence.

PrICE, S. (2012): "Religious Mobility in the Roman Empire", Journal of Roman Studies 102, 1-19 (http://dx.doi.org/10.1017/S0075435812000056).

Prowse, T. ET ALII (2007): "Isotopic evidence for age-related immigration to imperial Rome", American Journal of Physical Anthropology 132, 510-519 (http://dx.doi.org/10.1002/ ajpa.20541).

PuRCELL, N.

(1990): "Mobility and the Polis", [en] O. Murray - S. Price (eds.), The Greek City from Homer to Alexander, Oxford, 29-58.

(2004): "The boundless sea of unlikeness? On defining the Mediterranean", Mediterranean Historical Review 18/2, 9-29 (http://dx.doi.org/10.1080/0951896032000230462).

(2005): "Statics and dynamics. Ancient Mediterranean urbanism", [en] R. Osborne - B. Cunliffe (eds.), Mediterranean Urbanization 800-600 BC, Oxford, 249-272.

RATHBONE, D.

(2003): "The financing of maritime commerce in the Roman empire, I-II AD", [en] E. Lo Cascio (ed.), Credito e moneta nel mondo romano. Atti degli Incontri capresi dell'economia antica (Capri 12-14 ottobre 2000), Bari, 181-229.

(2009): "Merchant Networks in the Greek World. The impact of Rome", [en] Malkin Constantakopoulou - Panagopoulou (eds.), 2009, 299-310.

Rouse, I. (1986): Migrations in Prehistory. Inferring Population Movement from Cultural Remains, New Haven.

SALLARES, R.

(1991): The Ecology of the Ancient Greek World, London.

(2002): Malaria and Rome. A history of malaria in ancient Italy, Oxford-New York (http:// dx.doi.org/10.1093/acprof:oso/9780199248506.001.0001).

SCHEIDEL, W.

(1997): "Quantifying the sources of slaves in the early Roman Empire", Journal of Roman Studies 87, 156-169 (http://dx.doi.org/10.1017/S0075435800058123).

(2001): "Progress and problems in Roman demography", [en] Scheidel (ed.), 2001, 1-81.

(2003): "Germs for Rome", [en] Edwards - Woolf (eds.), 2003, 158-176.

(2004): "Human mobility in Roman Italy I: the free population", Journal of Roman Studies 94, 1-26 (http://dx.doi.org/10.1017/S0075435800064157).

(2007): "Demography", [en] W. Scheidel - I. Morris - R. P. Saller (eds.), Cambridge Economic History of the Greco-Roman World, Cambridge, 38-86 (http://dx.doi.org/10.1017/ CHOL9780521780537.004).

Scheidel, W. (ED.), (2001): Debating Roman Demography (=Mnemosyne, Bibliotheca Classica Batava. Supplement 211), Leiden-Boston-Köln.

SHAw, B. D. (2001): “Challenging Braudel. A New Vision of the Mediterranean”, Journal of Roman Archaeology 14, 419-53.

Storey, G. R. (ED.), (2006): Urbanism in the Preindustrial World. Cross-cultural approaches, Tuscaloosa.

TAlbert, R. J. A.

(2010): Rome's World. The Peutinger map reconsidered, Cambridge. 
(2012): "Roads not featured. A Roman failure to communicate?”, [en] Alcock - Bodel Talbert (eds.), 2012, 235-254 (http://dx.doi.org/10.1002/9781118244326.ch12).

TCHERnIA, A. (2011): Les romains et le commerce, Naples.

Torrence, R. (1986): Production and Exchange of Stone Tools. Prehistoric Obsidian in the Aegean, Cambridge.

WALSER, G.

(1989): "Quelques hypothèses sur le splendidissimum corpus mercatorum Cisalpinorum et Transalpinorum", Ktema 14, 89-93.

(1991): “Corpus mercatorum cisalpinorum et transalpinorum”, Museum Helveticum 48/3, 169-175 (http://dx.doi.org/10.5169/seals-37703).

Wells, J. C. K. - Stock, J. T. (2012): “The biology of human migration. The ape that won't commit?", [en] M. H. Crawford - B. C. Campbell (eds.), Causes and Consequences of Human Migration. An evolutionary perspective, New York, 45-64 (http://dx.doi.org/10.1017/ CBO9781139003308.005).

WIERSCHOWSKI, L.

(1995): Die regionale Mobilität in Gallien nach den Inschriften des 1. bis 3. Jh. n. Chr. Quantitative Studien zur Sozial- und Wirtschaftsgeschichte der westlichen Provinzen des Romischen Reiches (=Historia Einzelschriften 91), Stuttgart.

(2001): Fremde in Gallien- "Gallier” in der Fremde: die epigraphisch bezeugte Mobilität in, von und nach Gallien vom 1. bis 3. Jh. n. Chr. (Texte-Übersetzungen-Kommentare), (=Historia Einzelschriften 159), Stuttgart.

Wilkinson, J. (1982): Egeria's Travels to the Holy Land, Warminster.

WoOLF, G.

(2011): Tales of the Barbarians. Ethnography and empire in the Roman west, MaldenOxford (http://dx.doi.org/10.1002/9781444390810).

(2013): "Female Mobility in the Roman West", [en] E. Hemelrijk - G. Woolf (eds.), Women and the Roman City in the Latin West, Leiden-Boston, 351-368. 